\title{
Novel hydrogen gas sensor based on PANI and PANI coated $\mathrm{SnO}_{2}$ nanofibers
}

\author{
Hemlata J. Sharma*, Pallavi T. Patil and Subhash B. Kondawar \\ Department of Physics, R. T. M. Nagpur University, Nagpur - 440033, India \\ *Email: hemlatasharma208@gmail.com
}

The $\mathrm{SnO}_{2}$ nanofibers were synthesized by using Polyvinylpyrrolidone (PVP) nanofibers as template through electrospinning technique and calcination procedure. After calcination at 300 ${ }^{\circ} \mathrm{C}$ for $4 \mathrm{~h}$, the organic PVP core should be decomposed absolutely for pure $\mathrm{SnO}_{2}$. Due to the high thermal stability, the $\mathrm{SnO}_{2}$ shell should not break down at this temperature. So $\mathrm{SnO}_{2}$ nanofibers will be obtained. $\mathrm{SnO}_{2}$-Polyaniline $\left(\mathrm{SnO}_{2} / \mathrm{PANI}\right)$ heterostructure sensors have been developed for sensing hydrogen gas at room temperature with high specificity. $\mathrm{SnO}_{2} / \mathrm{PANI}$ heterostructure has been prepared and the heterostructures have been optimized by chemical deposition of PANI on nanofibers of $\mathrm{SnO}_{2}$ (size $\sim 200 \mathrm{~nm}$ ). The as-grown films were studied for some of the useful physicochemical properties i.e. X-ray diffraction (XRD), FTIR, UV-VIS, scanning electron microscopy (SEM) and Energy Dispersive X-ray Spectroscopy (EDX). Study of SEM micrograph revealed that pure $\mathrm{SnO}_{2}$ nanofibers were $\sim 200 \mathrm{~nm}$ and when PANI was coated then diameter increased to $\sim 300 \mathrm{~nm}$ due to the micellar templates of PANI around them. The possible incorporation of $\mathrm{SnO}_{2}$ in PANI matrix has been revealed from FTIR and UV-VIS spectra. The presence of tetragonal and crystalline structure of $\mathrm{SnO}_{2}$ was not affected with the incorporation of PANI as confirmed from XRD pattern. XRD studies showed peak broadening and the peak positions shift from standard values, indicating presence of tin oxide in nanoparticles form in the polyaniline (PANI) matrix. The $\mathrm{SnO}_{2} / \mathrm{PANI}$ composite sensor exhibited good sensitivity and much higher response magnitude towards $\mathrm{H}_{2}$ gas than the sensor based on PANI alone. Figure 1 shows the Sensitivity-Concentration graph of PANI and $\mathrm{SnO}_{2} / \mathrm{PANI}$ composite nanofibers [1].

Space charge modulation occurring at various interfaces such as $\mathrm{SnO}_{2} / \mathrm{PANI}$ interface and boundaries between the $\mathrm{SnO}_{2}$ nanograins explains the high toxic gas sensitivity observed for the $\mathrm{SnO}_{2} / \mathrm{PANI}$ heterostructured nanofibres thin film sensor. Figure 2 shows the mechanism of change in resistance of composite nanofibers for hydrogen gas [2].

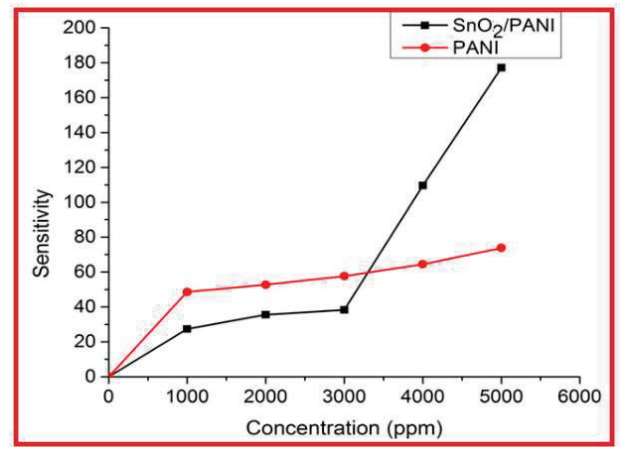

Figure 1: Sensitivity-Concentration graph of PANI and $\mathrm{SnO}_{2} / \mathrm{PANI}$ composite nanofibers.

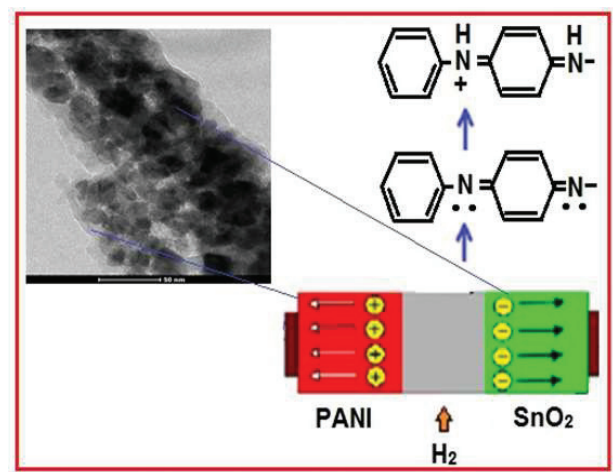

Figure 2: Mechanism of change in resistance of composite nanofibers for hydrogen gas.

The hybrid showed higher response and good sensitivity towards hydrogen gas as compared to pure PANI and pure $\mathrm{SnO}_{2}$ based sensors reported in earlier studies.

\section{References}

1. J. Q. Zhao, P. P. Wang, L. L. Feng, L. J. Zhou, D. J. Wang, G. D. Li, Sensors and Actuators B: Chemical, 191, (2014), 659-664.

2. S. B. Kondawar, S. P. Agrawal, S. H. Nimkar, H. J. Sharma, P. T. Patil, Advanced Materials Letters, 3, (2012), 393-398. 